the Ophthalmic Committee of the British Medical Association and of the Prevention of Blindness Committee.

The Council desires to thank the Council of the Royal Society of Medicine for the use of its rooms for meetings.

As in former years, the expenses of the Council have been defrayed by contributions from its members.

\title{
OPHTHALMOLOGICAL SOCIETY OF THE UNITED KINGDOM ANNUAL CONGRESS, 1933
}

The President Dr. A. H. H. Sinclair in opening the Annual Congress of the Ophthalmological Society of the United Kingdom extended a welcome to members of the society and foreign guests. He expressed regret at the loss of those members who had died during the last year and paid particular tribute to the work of Professor Priestley Smith, Mr. A. Freeland Fergus, Mr. Treacher Collins and Mr. J. Herbert Fisher. The President then awarded the Nettleship Prize to Mr. W. S. Duke-Elder for his work on the physiology of the eye.

Mr. Frank Law read a paper " On the Present Position of Ultraviolet Therapy in Eye Disease." He referred to the administration of the phototherapeutic department at Moorfields, the need for regular attendance of the patient, supervision and follow-up work. He described the technique of general and local phototherapy; the apparatus employed and the results obtained in the treatment of blepharitis, conjunctivitis, episcleritis, hordeola, corneal ulcers, various forms of keratitis and iridocyclitis. Sir Arnold Lawson, Mr. Davies, Mr. Lindsay Rea and Mr. Goulden took part in the discussion. The latter spoke of the importance of sending cases of phlyctenular conjunctivitis to the nose and throat surgeon for attention to the adenoids and tonsils. Mr. Goulden also stated that the results of ultra-violet treatment in cases of tuberculous iridocyclitis are by no means so disappointing as is generally believed. Persistence in treatment is essential. Tuberculin is of value as a therapeutic adjunct.

Mr. R. Foster Moore read a paper upon "The Value and Technique of the use of Radon in certain Intra-ocular Conditions." He dealt with the selection of the type of case for which radiotherapy was a justifiable procedure; the technique of access and application of the radon and the changes observed as a result of this treatment. He showed illustrations of cases of sarcoma of the choroid, glioma of the retina and angiomatosis retinae treated by radon. He alluded to the possibility of producing, by means 
of radon an obliterative endarteritis in cases of recurrent vitreous haemorrhages (Eales' disease).

Mr. H. B. Stallard followed with a paper on "The Effects of Radium Emanations in certain selected Diseases of the Eye." This paper was illustrated by microphotographs of two cases of sarcoma of the choroid, one of sarcoma of the iris and two of glioma retinae subjected to the interstitial and scleral methods of applying screened radon seeds of various strengths, and in one case the use of an unscreened circular applicator containing $10 \mathrm{mgms}$. of radium salt was employed. Serial sections of the irradiated material were taken and the zone of effective irradiation carefully measured in each case. A comparison of the different methods of application was made and inferences deduced from these.

Mr. A. D GRiffith read a "Report on a Case of Glioma Retinae Treated by Surface Applications of Radium, with Pathological Findings." Radium was used in the form of screened needles embedded in a plaque, the initial dose amounting to 5040 mgm. hours. Most of the neoplasm disappeared except a localised area near the optic disc which contained a few calcareous granules and was believed to be degenerate. Later, recurrence occurred elsewhere in the eye and radiotherapy on this occasion was ineffective. The neoplasm increased and extra-ocular extension took place. $\mathrm{Mr}$. H. Neame suggested that the external application of radium might by preferable, as it avoided disturbance of the malignant cells by the insertion of a seed.

Mrs. P. P. MarTiN read a paper on "The Effect of Irradiation of the Eye." Her work has been done on 34 cases in which the eye was normal but where the orbital adnexa were the site of malignant disease and under radium treatment. She described the effects of such treatment on the lids, conjunctiva, cornea, iris, lens and retina. The paper was admirably illustrated by photographs.

At the afternoon session Dr. Ivy Mackenzie, Dr. Spence Meighan and Dr. E. N. Pollock read a most interesting paper "On the Projection of the Retinal Quadrants on the Lateral Geniculate Bodies, and the Relationship of the Quadrants to the Optic Radiations." Their material was taken from a patient who had a syphilitic lesion of the geniculate body on one side who committed suicide the day after her visual fields and medical examination had been made. Serial sections were cut from geniculate bodies to the occipital poles and an exhaustive examination of these sections carried out. Some interesting points about the blood supply of the geniculate body and the representation of the lower retinal quadrants on the lateral side and the upper on the mesial side of the geniculate body were discussed.

Sir John Parsons, Mr. Leslie Paton, Dr. Traquair and Dr. 
Greenfield expressed their appreciation of this paper and joined in the discussion.

Dr. J. G. Greenfield and Dr. S. Nevin described "The Pathology of a late Infantile Case of Amaurotic Idiocy, with the Macular appearances of Tay-Sachs' Disease." The literature and pathological findings of previous cases were revealed and criticised. The authors of this paper showed some excellent microphotographs which demonstrated that the typical fundus picture of this disease is due to the presence of lipoids and lipoid degeneration in the ganglion cells in the vicinity of the macula. Sir John Parsons, in the discussion that followed, outlined certain definite types of amaurotic idiocy with macular changes. Mr. Leslie Paton also contributed to the discussion.

Dr. J. E. Caughey read a paper on "Cataract in Dystrophia Myotonica." He described the clinical findings, the comparative rarity of this disease, and its heredito-familial nature associated with a decline in family fortunes with each generation as the defects of dystrophia myotonica became added to cataract and then mental deficiency superimposed on these. The slit-lamp appearances of the type of cataract seen in this disease were discussed.

Dr. W. Clark Souter followed with a paper on "A Case of Cataract Extraction in Myotonia Atrophica." He described his investigations of the family history of five generations affected by this disease, and gave an account of the operative technique he employed in the treatment of these cases and the results obtained. Some good photographs and charts accompanied this paper.

Mr. Juler and Mr. Summers spoke of similar cases on which they had operated.

Friday, May 12.

Dr. John Marshall and Dr. I. Chesar Michaelson read a paper on "Exudative Retinitis in Children." They described four cases and showed microphotographs of the large swollen 'ghost' cells in the retina and sub-retinal fluid, coagulum in the retina and detachment. They discussed the toxic origin of this disease, its course, histological interpretation and its distinction from that type of exudative retinitis described by Coats.

Mr. Neame and Dr. Spence Meighan joined in the discussion.

Professor Reginald Punnett gave an address entitled "An Ocular Mendelian Puzzle." He described the chromosomal interpretation of sex linked inheritance; the transmission of hereditary disease through female 'conductor' chromosomes; the presence of a sex determining chromosome and a 'deficiency' chromosome in the male. This admirable contribution must be read in full in order to appreciate Professor Punnett's arguments. 
Mr. C. H. Usher opened the discussion on "Heredity and Eye Diseases." He showed charts of many pedigrees and spoke of the difficulty in assessing the relative effects of heredity and environment in certain diseases. He discussed those solitary cases of eye disease occurring in unaffected families and the existence of 'carriers.'

Dr. M. VAN DUYSE followed and gave illustrations of hybridation from two varieties, dominant and recessive, in flowers and mice. He described examples of direct and indirect heredity in cases of incest and the consanguineous marriages of cousins. His paper was much appreciated by the society.

Miss Julia Bell spoke of the Mendelian laws of heredity, their theory, interpretation and the necessity for their modification in certain instances. The mathematical problem of hereditary disease is one of great complexity. The collection of reliable and sufficient clinical data is important, so also is attention to the anomalous pedigree.

Miss IDA MANN described the experimental production of isolated anomalies and hereditary defects by mechanical, thermal, chemical, and irradiational agents and the transmissibility of acquired characters. She demonstrated by means of diagrams and drawings alterations in the structure of unicellular organisms induced by experimental methods. In the case of mammals experimental attempts to produce hereditary eye defects had so far failed. In the case of human beings some interesting results had been obtained by irradiating the pregnant uterus at the third month of foetal life. Epithelial rosettes and other changes significant of arrested development and differentiation of the nuclear layers of the retina were evident on examination of the eyes. Mr. Myles Bickerton and Mr. Leslie Paton spoke in the discussion.

In the afternoon a clinical meeting was held at the Central London Ophthalmic Hospital and cases were shown.

In the evening Dr. H. M. TraguaIR read a paper concerning "Two Cases of Recurrent Spasm of the Central Artery of the Retina." He drew attention to the recurrence of the attacks as a point of differentiation from thrombosis and embolism of this artery. The blindness produced by retinal spasm was distinct from that of a scintillating scotoma of migraine, the former being produced by peripheral vascular changes and the latter by alteration in the cerebral circulation.

Mr. L. H. Savin read a paper entitled "A Discussion of the Relationship, Direct or Indirect, between certain cases of Herpes Ophthalmicus and Varicella." He gave an account of 18 cases, some of whom had had herpes zoster before varicella, others varicella before herpes zoster, and one had suffered from varicella 
and herpes zoster simultaneously. He discussed the nature of the infecting agent, inoculation and immunity experiments. He stated that probably both diseases were caused by modified strains of the same virus. In the discussion that followed Mr. Leslie Paton said that the mode of entry for the infecting agent was along the lymphatics of nerves in the nose and throat in cases of herpes and by the blood stream in cases of varicella.

Mr. R. C. Davenport, Mr. Quick and Dr. Rao gave accounts of cases.

Mr. W. S. Duke-Elder read a paper "A factor in the Aetiology of Glaucoma." He confined his remarks to the part played by the vitreous body in cases of chronic glaucoma and the mechanism of a vascular crisis in acute glaucoma. He described with diagrams and charts of drum-tracings certain animal experiments elaborated to produce a vascular crisis. The parts played by histamine and the 'axon reflex' were discussed.

Mr. Williamson-Noble, Mr. Alabaster, Dr. Traquair and Mr. Michaelson joined in the discussion.

Saturday, May 13.

Mr. RidDell read a paper on "Coeliac Disease Associated with Night-blindness." He described the diet of this patient which was defective in fats and proteins but not in vitamin A. The diet was corrected and the night-blindness disappeared in 10 days. The patient was unable to absorb fats and had a dislike for meat, the ingestion of which produced certain toxic symptoms. There was no response to cod liver-oil and liver.

Dr. Rao in the discussion that followed this paper described cases of night-blindness due to toxaemia from biliary cirrhosis, chronic diarrhoea, pregnancy, saccharine poisoning, protozoal and parasitic infections.

Mr. C. D. Shapland read a paper on " Endothermy Cauterization for Detachment of the Retina." He described the technique employed at Utrecht and that of Larsson in Stockholm. He gave valuable statistics about the refractive errors, sites and types of retinal tears, complications and results of 133 cases of retinal detachment treated at Moorfields Eye Hospital by the Larsson technique. Messrs. Goulden, Neame, Juler, Whiting and Traquair joined in the discussion.

Mr. AfFleck Greeves described a conjunctival suture which he uses in cataract operations before the section is made. The object of the suture is to co-apt the edges of the corneo-scleral section wound, to expedite firm healing, and to minimise astigmatism. It is especially indicated in cases of fluid vitreous, hypermature cataract, subluxated lens, loss of vitreous and where movements are unavoidable such as in cases of rheumatism and chronic bronchitis. 
Mr. J. H. Doggart read a paper on "Ocular Crystals." $\mathrm{He}$ gave an account of the history and literature of this subject and described the types of crystals seen in the cornea, anterior chamber, lens, vitreous and retina and their association with certain diseases of the eye. This paper was illustrated by drawings of slit-lamp examinations.

Mr. E. WolfF contributed a paper on "Relative Ptosis" and described cases where the widening of the palpebral fissure on the opposite side to the relative ptosis was the sign of pathological importance

Mr. J. N. TEnNent reported two cases of carcinoma of the lacrymal sac; in one case the neoplasm originated from the columnar epithelium of the lacrymal sac and in the other the disease arose in the nose and infiltrated the sac. Primary carcinoma of the lacrymal sac is.very rare. This paper was illustrated by some good microphotographs.

\section{Museum of Scientific Exhibits}

A museum of scientific exhibits was held in the College of Nursing. Macroscopic and microscopic specimens of pathological interest were on view. Among the other exhibits were a series of composite slit-lamp drawings made from living animals in the London Zoo; drawings of abnormalities of the iris; a collection of antique instruments ; ; the strabismoscope; the orthoptoscope; instruments of historic interest; and rubber occluder spectacles for squinters.

Theodore Hamblin, Ltd., were good enough to undertake the structural arrangements for this museum.

\section{Trade Exhibition}

A trade exhibition was held in the College of Nursing and many instruments of interest were shown and demonstrated. The following firms had stands:-T. Bowing \& Co., Ltd.; Clifford Brown, Ltd.; Clement Clarke, Ltd.; Curry \& Paxton, Ltd.; C. W. Dixey \& Son; Down Bros., Ltd.; Theodore Hamblin, Ltd.; Alfred Hawes \& Son ; C. Davis Keeler ; H. K. Lewis \& Co., Ltd.; Pankhurst \& Barrett; Rayner \& Keeler, Ltd.; Uni-Lux Optical Co. ; John Weiss \& Son, Ltd. ; Carl Zeiss \& Co., Ltd.

The Annual Dinner was held on Thursday May 11, at the Langham Hotel, the President, Dr. A. H. H. Sinclair being in the chair.

Members of the society and their friends visited the Zoological Society's Gardens, Whipsnade Park on Saturday afternoon May 13.

H. B. Stallard. 